\title{
HAYEK \\ Y SAN JUAN PABLO II
}

\author{
LEÓN GÓMEZ RIVAS*
}

Fecha de recepción: 3 de marzo de 2014.

Fecha de aceptación: 30 de junio de 2014.

Desde hace algunos años asistimos a un estimulante debate alrededor de la Doctrina Social de la Iglesia Católica y su mayor o menor entendimiento con el liberalismo económico. Creo haberles ya mencionado aquí ese interesante libro de los profesores Rodríguez Braun y Rallo (El liberalismo no es pecado), que juega con el título de otro famoso acerca ciertas incomprensiones sobre cuál deba ser el ámbito de la libertad de opinión de un cristiano respecto a las actividades económicas, políticas, etc. (al que añado Liberalismo, catolicismo y ley natural, de Francisco José Contreras). Del mismo modo que también es conveniente explicar a ciertos académicos particularmente laicistas qué significa el Magisterio de la Iglesia y cómo se entiende la diferencia entre las cuestiones de fe y la libertad de las conciencias en el día a día de los creyentes.

La Encíclica Caritas in Veritate (2009) de Benedicto XVI volvió a despertar estas discusiones, que más recientemente han vuelto a suscitarse con la Exhortación Apostólica Evangelii Gaudium (2013) del Papa Francisco, escrita en un sentido bien distinto de los académicos documentos de su antecesor. Hace apenas un mes tenía lugar un concurridísimo seminario de AEDOS en torno a $E G$, donde se ponían bien de manifiesto las diferentes posturas sobre el tema; que pueden completar con la abultada documentación que les ofrece la web del Centro Diego de Covarrubias apoyándose muchas veces en la mayor experiencia del Instituto Acton Argentina y otros thinktanks anglosajones.

Evidentemente, no voy a resolver este complejo asunto en unas pocas líneas (ni siquiera creo que haya una única solución para

\footnotetext{
* Universidad Europea de Madrid.
} 
ese debate). Al revés, me permitirán que confunda un poco más los ánimos refiriéndome a un tercer Papa, Juan Pablo II (que la Iglesia elevará a los altares el próximo mes de abril). Juan Ramón Rallo lo citaba aquí ya el año 2005, a propósito de varias encíclicas sobre cuestiones económicas, que marcaron un giro muy interesante en la Doctrina Social de la Iglesia. Es famosa, por ejemplo, esta valiente y bastante incomprendida apuesta por el modelo capitalista "si por "capitalismo" se entiende un sistema económico que reconoce el papel fundamental y positivo de la empresa, del mercado, de la propiedad privada y de la consiguiente responsabilidad para con los medios de producción, de la libre creatividad humana en el sector de la economía» (Centesimus Annus, 1991).

Pues bien, en torno a la redacción de esta Encíclica (y, en general, al conocimiento de la Economía que tuvo ese Papa), pueden encontrarse en la web varias referencias a una supuesta entrevista de Juan Pablo II con Friedrich Hayek y la posible influencia del premio Nobel sobre el pensamiento económico del Papa Wojtyla. En España, lo ha repetido varias veces Jesús Huerta de Soto, a partir de su semblanza sobre Hayek publicada en La Ilustración Liberal el año 1999: «en 1992, el pensador católico Michael Novak sorprendió al mundo intelectual cuando hizo pública la extensa conversación personal que el Papa Juan Pablo II y Hayek mantuvieron antes del fallecimiento de éste, de manera que existen signos inequívocos de la gran influencia que el pensamiento de Hayek tuvo en la encíclica Centesimus annus y en particular en sus capítulos 31 y 32, todos ellos llenos de importantes aportaciones hayekianas». Esta misma referencia la volvió a utilizar el profesor Huerta de Soto en su artículo sobre Hayek para la página web liberalismo.org.

Por curiosidad, he seguido la pista sobre esta afirmación (animado por el catedrático Victoriano Martín, al que dedico este pequeño rastreo anticipándome a su Iubilatio), y puedo añadir los siguientes datos: por una parte, el propio Huerta de Soto precisa mejor la cita de Novak en su libro Nuevos estudios de Economía Política (2002), concretamente en el capítulo VIII al hablar de «La doctrina social de la Iglesia Católica y la Escuela Austriaca de Economía». Aquí nos indica la fuente empleada, un párrafo de Michael Novak publicado en Economic Affairs que les copio: «During 
the last months of his life, Hayek had the opportunity for a long conversation with Pope John Paul II. There are signs of Hayek's influence in certain portions of the Pope's encyclical Centesimus Annus. In sections 31 and 32 in particular Centesimus Annus employs unmistakably Hayekian insights». Michael Novak, «Two Moral Ideas for Business (The Hayek Memorial Lecture, 22 June 1992, London, England)», Economic Affairs, septiembre-octubre 1993, p. 7. Y un poco más adelante refuerza este argumento con la referencia a otra posible influencia del pensamiento de Israel Kirzner, conocido economista austriaco, sobre Juan Pablo II al señalar «el gran paralelismo existente entre la concepción de la acción humana creativa desarrollada por el Papa en su tesis doctoral titulada Persona y acción, y la concepción de la función empresarial que debemos a Kirzner (Michael Novak, The Catholic Ethic and the Spirit of Capitalism, The Free Press, Macmillan International, Nueva York, 1993)».

Finalmente, quiero añadir una última pista sobre esa hipotética conversación de Hayek con Juan Pablo II, en este caso a partir del artículo sobre Hayek en la Wikipedia: «In 1980, Hayek, a nonpracticing Roman Catholic, was one of twelve Nobel laureates to meet with Pope John Paul II, to dialogue, discuss views in their fields, communicate regarding the relationship between Catholicism and science, and bring to the Pontiff's attention the problems which the Nobel Prize Winners, in their respective fields of study, consider to be the most urgent for contemporary man». Para lo que cita un documento PDF del Cato Institute (se trata de la transcripción de una entrevista con Lanny Ebenstein en una especie de Book Forum) que no he podido localizar. Sin embargo, sí ofrece otra referencia que puede resultarle de interés al lector curioso que haya perseverado hasta aquí: el libro del personaje entrevistado, Alan O. Ebenstein, Friedrich Hayek: A biography (2003), páginas 301 y 305. Ya me dirán si les ha convencido o no este argumentario. 
